\title{
A study of congenital anomalies in a tertiary care hospital in North East region, India
}

\author{
Kangjam Radhesana Devi ${ }^{1}$, R. K. Praneshwari Devi ${ }^{1 *}$, Jyoti Priya ${ }^{1}$, \\ Ahanthembi Sanaton ${ }^{2}$, Leimapokpam Roshan Singh ${ }^{1}$, Lalhlimpuii Murray ${ }^{1}$
}

\begin{abstract}
${ }^{1}$ Department of Obstetrics and Gynaecology, Regional Institute of Medical Sciences, Imphal, Manipur, India
${ }^{2}$ Department of Obstetrics and Gynaecology, Jawaharlal Nehru Institute of Medical Sciences, Imphal, Manipur, India
\end{abstract}

Received: 06 May 2018

Revised: 23 May 2018

Accepted: 30 May 2018

\section{*Correspondence:}

Dr. R. K. Praneshwari Devi,

E-mail: praneshwarirk1@gmail.com

Copyright: () the author(s), publisher and licensee Medip Academy. This is an open-access article distributed under the terms of the Creative Commons Attribution Non-Commercial License, which permits unrestricted non-commercial use, distribution, and reproduction in any medium, provided the original work is properly cited.

\section{ABSTRACT}

Background: Congenital anomalies are important cause of morbidity and mortality in newborns and are defined as structural and functional abnormalities including metabolic disorders present at birth. These defects are of prenatal origin resulting from defective embryogenesis or intrinsic abnormalities in the process of development and are associated with various risk factors.

Methods: Our study is a cross-sectional study done at Regional Institute of Medical Sciences, Imphal over period of one and half years from May 2016 to October 2017. Aim of study was to find out incidence of congenital anomalies and proportions of different types of congenital anomalies. Outcome was studied in relation to maternal age, religion, parity, gestational age, sex of baby, outcome and birth weight of baby.

Results: Total numbers of congenital anomalies were 91 out of 13658 births. Incidence of congenital anomalies was $0.66 \%$. Most common congenital anomaly was cleft lip (17.6\%) followed by CTEV (13.2\%) and was more common among male term babies. These were most common in 18-24 years of maternal age group (34.1\%) followed by 30-34 years $(26.4 \%)$ and among women of parity P0-P2.

Conclusions: Congenital malformations are a major cause of still births and infant mortality. A level II targeted scan should be done at 18-20 weeks to find out anomalies and reduce the prevalence. There should be widespread education in the community regarding the common congenital malformations, their outcomes and possible available modes of treatment.

Keywords: Anomalies, Newborn, Targeted scan

\section{INTRODUCTION}

Congenital anomalies are defined as structural or functional anomalies that occur during intrauterine life. These anomalies result from defective embryogenesis or intrinsic abnormalities in process of development and are prenatal in origin.
Birth defects can be isolated abnormalities or part of a syndrome and are one of the most important cause of neonatal morbidity and mortality both in developed and developing countries. ${ }^{1}$ In developing country like India due to the high incidence of infectious diseases, nutritional disorders and social stress, the development defects are often over shadowed, but the present scenario 
is changing rapidly. Congenital anomalies accounts for 8$15 \%$ of perinatal deaths and $13-16 \%$ of neonatal deaths in India. $^{2}$ There are several known factors that are associated with birth defect such as maternal TORCH infection, genetic factors, drugs, maternal age, consanguinity etc.

Due to congenital anomalies 3,03,000 newborns die within 4 weeks worldwide every year and Contribute to significant morbidity and mortality in newborns. ${ }^{3}$ Most common congenital anomalies are cardiovascular diseases, neural tube defects and Down syndrome.

Major anomalies have serious medical, surgical and cosmetic consequences. It contributes to long term disability, which may have significant impacts on individuals, families, health-care systems and societies.

The aim of study was to find out incidence of congenital anomalies and proportion of different types of congenital anomalies among abortus, still born and live born fetuses.

\section{METHODS}

A descriptive cross-sectional study was done in Department of Obstetrics and Gynaecology, RIMS, Imphal, Manipur. This study included abortions, still births and newborns delivered at RIMS, Imphal. Data was collected from May 2016 to October 2017 using a structured form containing details of maternal age, gestation at delivery, mode of delivery, sex, birth weight and outcome of baby, parity of mother, history of congenital malformations in previous pregnancies, consanguinity. They were examined soon after birth for major and or minor congenital defect.

Diagnosis of congenital anomalies was based on clinical evaluation of new born babies by the paediatrician and consultant neonatologist. A detailed general physical and systemic examination of the babies was carried out. Antenatal ultrasonography findings were noted. Immediate outcome of all malformed babies were recorded during the period of the mothers hospital stay. No autopsy examinations were carried out.

Out of 13685 births 91 were congenital anomalies. Congenital anomalies were divided into craniospinal, vascular, musculoskeletal, gastrointestinal, genitourinary, cardiovascular and chromosomal. Data analysis was done using simple descriptive statistics.

\section{RESULTS}

In this study 91 babies out of total 13,658 births had congenital anomalies. Incidence being $0.66 \%$, few babies had more than one congenital anomalies. Congenital anomalies were most commonly found in maternal age group of 21-30 years (48.3\%) (Table 1) followed by 31 40 years $(37.5 \%)$ and also more common among Hindu (71.4\%) (Table 2) followed by Muslim.
Table 1: Age distribution of congenital anomalies.

\begin{tabular}{|lll|}
\hline Age group & No. of pregnant women & Percentage \\
\hline$\leq 20$ years & 12 & 13.2 \\
\hline $21-30$ years & 44 & 48.3 \\
\hline $31-40$ years & 35 & 37.5 \\
\hline
\end{tabular}

Table 2: Distribution of congenital anomalies according to religion.

\begin{tabular}{|lll|}
\hline Religion & No. of pregnant women & Percentage \\
\hline Hindu & 65 & 71.4 \\
\hline Muslim & 18 & 19.8 \\
\hline Christian & 8 & 8.8 \\
\hline
\end{tabular}

Among the study groups $50.5 \%$ cases were among primigravidas followed by primiparas which were $27.5 \%$ (Table 4).

Congenital anomalies were found to be most common among term babies with gestational age >37-40 weeks $(53.8 \%)$ (Table 3 ) followed by the babies with gestational age $28-37$ weeks $(31.9 \%),<28$ weeks $(6.6 \%)$ and all were singleton births. Most of them were unbooked cases with infrequent antenatal check up without any anomaly scan. $65 \%$ of the mothers have history of previous spontaneous abortion. Among the post dated babies congenital anomalies were found to be $7.7 \%$.

Table 3: Distribution of congenital anomalies according to gestational age.

\begin{tabular}{|lll|}
\hline Gestational age & No. of patients & Percentage \\
\hline$<28$ weeks & 6 & 6.6 \\
\hline $28-37$ weeks & 29 & 31.9 \\
\hline$>37-40$ weeks & 49 & 53.8 \\
\hline$>40$ weeks & 7 & 7.7 \\
\hline
\end{tabular}

Table 4: Distribution of congenital anomalies and parity.

\begin{tabular}{|lll|}
\hline Parity & No. of patients & Percentage \\
\hline P0 & 46 & 50.5 \\
\hline P1 & 25 & 27.5 \\
\hline P2 & 13 & 14.3 \\
\hline$\geq$ P3 & 7 & 7.7 \\
\hline
\end{tabular}

\section{Distribution of congenital anomalies}

In the study, male babies $(57.1 \%)$ were more commonly affected than female babies $(38.5 \%)$. Out of 91 congenital anomalies 4 babies have ambiguous genitalia and most of the babies $(64.8 \%)$ delivered or expelled vaginally, LSCS was done in $28.6 \%$ and $6.6 \%$ were aborted. It was found that $50.5 \%$ babies were born with birth weight $>2500$ 4000 grams followed by $29.9 \%$ of babies with birth weight >1500-2500gms, $18.7 \%$ of babies with $<1500$ gms. $1.1 \%$ of babies have birth weigth $>4000$ gms. 
Congenital anomalies were seen more in live births, $69.2 \%$ in compared to still births which are $13.2 \%$.

The most common congenital anomalies in the study were musculoskeletal which $50.5 \%$ is but most of them are nonfatal but are main factor contributing for perinatal morbidity. Second most common anomaly is craniospinal $19.7 \%$. Cardiovascular anomalies were found to be least detected in this study group which is $1.09 \%$ (Table 5).

Table 5: Craniospinal anomalies.

\begin{tabular}{|ll|}
\hline Congenital anomalies & No. of babies \\
\hline Anencephaly & 8 \\
\hline Encephalocele & 2 \\
\hline Meningocele & 2 \\
\hline Hydrocephalus & 3 \\
\hline Holoprosencephaly & 1 \\
\hline Dandy walker malformation & 1 \\
\hline Microcephaly & 1 \\
\hline
\end{tabular}

Table 6: Vascular anomalies.

$\begin{array}{ll}\text { Vascular anomalies } & \text { No. of babies } \\ \text { Capillary hemangioma } & 1\end{array}$

Table 7: Cardiovascular.

\begin{tabular}{|ll|}
\hline Cardiovascular & No. of babies \\
\hline Left hypoplastic ventricle & 1 \\
\hline
\end{tabular}

Table 8: Musculoskeletal anomalies.

\begin{tabular}{|ll|}
\hline Congenital anomalies & No. of babies \\
\hline Cleft lip & 4 \\
\hline Cleft lip and Cleft palate & 12 \\
\hline Cleft palate & 1 \\
\hline CTEV & 12 \\
\hline Polydactyly & 4 \\
\hline Syndactyly & 1 \\
\hline Phocomelia & 1 \\
\hline Syrenomelia & 1 \\
\hline Limb deformities & 3 \\
\hline Mandibular hypoplasia & 1 \\
\hline Flat nasal bridge & 1 \\
\hline Absent philtrum & 1 \\
\hline Alveolar cyst & 1 \\
\hline Periauricular sinus & 1 \\
\hline Anotia & 1 \\
\hline Sacrococcygeal teratoma & 1 \\
\hline
\end{tabular}

It was found that among the musculoskeletal anomalies cleft lip (17.6\%) and CTEV (13.4\%) were the most common while anencephaly $(8.7 \%)$ was most common among craniospinal anomalies. Chromosomal anomalies, DOWN syndrome were detected in $7.6 \%$ of the cases. Incidence of gastrointestinal and genitourinary anomalies was more or less similar in this study group accounting for $9.8 \%$.

Table 9: Gastrointestinal system.

\begin{tabular}{|ll|}
\hline Congenital anomalies & No. of babies \\
\hline Omphalocele & 3 \\
\hline Gastroschisis & 4 \\
\hline Imperforate anus & 1 \\
\hline Diaphragmatic hernia & 1 \\
\hline
\end{tabular}

Table 10: Genitourinary system.

\begin{tabular}{|ll|}
\hline Congenital anomalies & No. of babies \\
\hline Micropenis & 2 \\
\hline Undescended testis & 1 \\
\hline Bifid scrotum & 1 \\
\hline Paraphimosis & 1 \\
\hline Ambiguous genitilia & 4 \\
\hline
\end{tabular}

Table 11: Chromosomal anomalies.

\begin{tabular}{|ll|}
\hline Congenital anomalies & No. of babies \\
\hline Down's Syndrome & $\mathbf{7}$ \\
\hline
\end{tabular}

About $80 \%$ of the babies were compatible with life $20 \%$ were non compatible. The increase in perinatal mortality was mainly due to associated preterm labour, prematurity and IUGR. The incidence of CNS anomalies was higher in the stillborn. History of consanguinity was seen in 3 out of 91 patients.

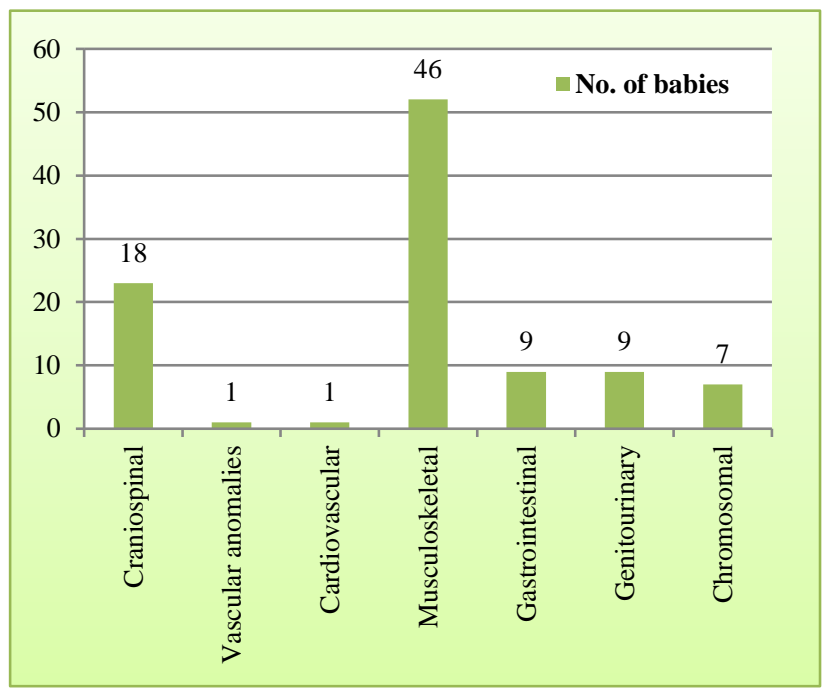

Figure 1: Gross distribution of congenital anomalies.

Table 12: Sex wise distribution of congenital anomalies.

\begin{tabular}{|lcc|}
\hline Sex of babies & No. of babies & percentage \\
\hline Male & 52 & 57.1 \\
\hline Female & 35 & 38.5 \\
\hline Ambiguous & 4 & 4.4 \\
\hline
\end{tabular}




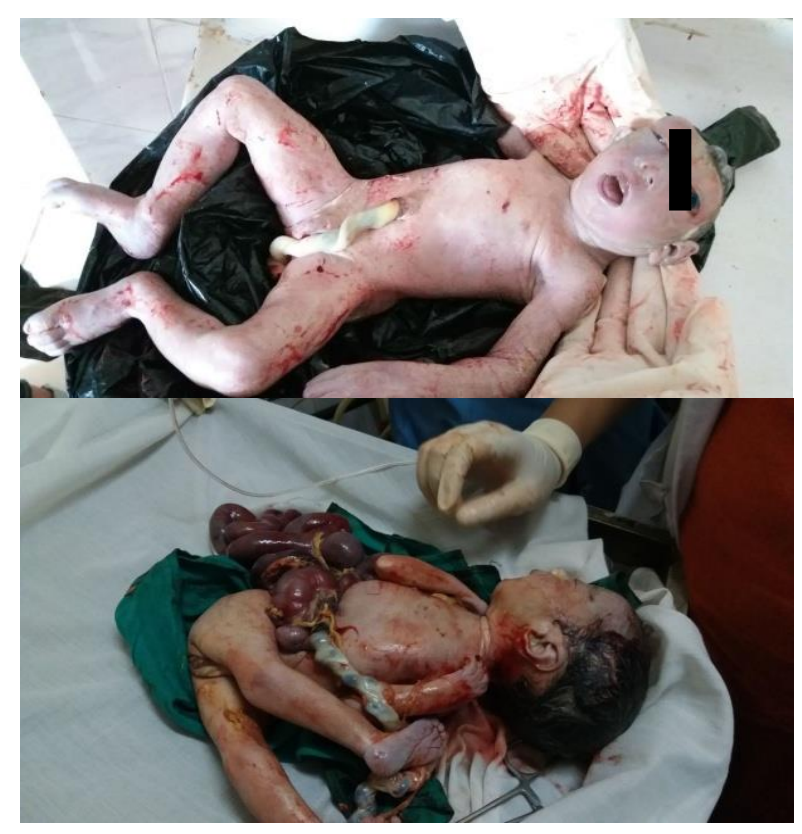

Figure 2: Anencephaly and gastroschisis.

Social awareness about consanguinity, preconceptional counselling, supplementation of folic acid, targeted level II scan can be done to reduce the incidence of congenital anomalies.

Table 13: Distribution of congenital anomalies and birth weight of babies.

\begin{tabular}{|llc|}
\hline Birth weight (grams) & No. of babies & Percentage \\
\hline$\leq 1500$ & 17 & 18.7 \\
\hline$>1500-2500$ & 27 & 29.7 \\
\hline$>2500-4000$ & 46 & 50.5 \\
\hline$>4000$ & 1 & 1.1 \\
\hline
\end{tabular}

Table 14: Mode of delivery among anomalous babies.

\begin{tabular}{|c|c|c|}
\hline Mode of delivery & No. of patients & Percentage \\
\hline $\begin{array}{l}\text { Vaginal delivery/ } \\
\text { expulsion }\end{array}$ & 59 & 64.8 \\
\hline LSCS & 26 & 28.6 \\
\hline Abortion & 6 & 6.6 \\
\hline
\end{tabular}

Table 15: Outcome of anomalous babies.

\begin{tabular}{|lll|}
\hline Outcome & No. of patients & Percentage \\
\hline Alive & 63 & 69.2 \\
\hline Intrauterine death & 7 & 7.6 \\
\hline Perinatal death & 9 & 9.9 \\
\hline Still birth & 12 & 13.2 \\
\hline
\end{tabular}

\section{DISCUSSION}

Congenital anomalies are important causes of still births and infant mortality, and are contributors to childhood morbidity. The pattern and prevalence of congenital anomalies may vary from time to time or with geographical location or racial differences. ${ }^{4}$ With improved infections and nutritional deficiency diseases, congenital malformations have become important causes of perinatal mortality in developing countries like India.

Incidence of congenital anomalies in our study is $0.66 \%$ which is more or less comparable to other studies in different parts of the country like Kokate P et al, Rani MS et al and Chowdhary $\mathrm{P}$ et al where the incidences were $0.9 \%, 0.9 \%$ and $1.06 \%$ respectively but it contradicts to Pabbati $\mathrm{J}$ et al where it is $4.08 \%{ }^{5-8}$ Most common congenital anomalies in this study are musculoskeletal followed by craniospinal, gastrointestinal, genitourinary etc. which is also comparable to Pabbati J et al study. But it contradicts many studies (Kokate $\mathrm{P}$ et al, Rani MS et al and Chowdhary $\mathrm{P}$ et al). The less number of neural tube defects can be explained by widespread antenatal iron folic acid prophylaxis. Male babies are more commonly affected than females and it coincides with other studies from India as well as outside. This can be explained by more lethal malformation in female babies.

In our study most of congenital anomalies (80\%) were compatible to life, which is also comparable to many other studies.

In this study congenital anomalies are most common among maternal age group of 21-30 years (48.3\%) in comparison to most of other studies which are more common in maternal ages of $>35$ years, this may be explained because of the increase in the number of early marriage among the study group. ${ }^{9}$ Previous studies have reported that significantly higher incidence of malformation among the mother of gravid 4 or more but our results contradict this as it is more common in primigravidas. The incidence of congenital anomalies was significantly higher in term babies compared to preterm babies which are not in accordance with many previous studies reported from this country. This different in pattern and prevalence may be explained by geographical location, environmental and genetic factors, socio cultural, racial and ethnic variables. Consanguineous marriages are reported to play a major role in the occurrence of congenital anomalies. ${ }^{10}$ In the present study also 3 out of 91anomalies are detected in consanguineous marriage.

Incidence of congenital malformed babies appears more nowadays as compared to past because of advanced diagnostic facilities and availability of neonatal intensive care unit which lead to increase chances of survival of malformed babies. Increasing awareness about prenatal care is the need of the hour.

\section{CONCLUSION}

As congenital anomalies are the major cause of still births and infant mortality the importance of regular ANCs should be understood by pregnant ladies, and prenatal screening for congenital anomalies should be done. If 
possible high risk pregnancies should be identified. A targeted level II scan should be done at 18-20 weeks to exclude anomalies.

Once anomaly is detected, discussions of various management options have to be done with parents, neonatologist, paediatric surgeon and neurosurgeon when necessary. Termination of pregnancy is a better option in case of lethal congenital anomalies.

Routine screening should be done even in low risk women since a cost of routine screening is not more than burden of a severely morbid and disabled child on family and society.

Funding: No funding sources Conflict of interest: None declared

Ethical approval: Not required

\section{REFERENCES}

1. Rosano A. Infant mortality and congenital anomalies from 1950 to 1994: an international perspective. J Epidemiol Community Health. 2000;54:660-6.

2. Bhat BV, Ravikumara M. Perinatal mortality in India-Need for introspection. Indian J Matern Child Health. 1996;7:31-3.

3. Congenital anomalies. Available at www.who.int/mediacentre/factsheets. Accessed on December 8, 2017.

4. Birch MR, Grayson N, Sullivan EA. AIHW Cat. NO. PER 23. Birth Anomalies Series No.1. Sydney: AIHW National Perinatal Statistics Unit; 2004.
5. Pabbati J, Subramanian P, Sudharshan RC, Sadhana N, Rao R. Study on incidence of congenital anomalies in a rural teaching hospital, Telangana, India. Int J Contemp Pediatr. 2016;3(3):887-90.

6. Rani Sandhya M, Lakshmi AA. Study of congenital malformations in a tertiary hospital, government general hospital, Guntur. J Dent Med Science. 2015;14(4):16-20.

7. Chowdhary P, Devi RKP, Singh LS, Thakare AS, Tamang ZD, Debroy S, et al. Clinical study on congenital malformations at birth in a tertiary level hospital in North-East India. J Dent Med Sci. 2017;16(1):24-27.

8. Kokate P, Bang R. Study of congenital malformation in tertiary care centre, Mumbai, Maharashtra, India. Int J Reprod Contracept Obstet Gynecol. 2016:6(1):89-93.

9. Suguna Bai NS, Mascarene M, Syamalan K, Nair PM. An etiological study of congenital malformation in the newborn. Indian Pediatr. 1982;19:1003-7.

10. Grag A, Canolly C, Hollier LM. Maternal age and malformations in singleton births. J Obstet Gynecol. 2000:96:701-6.

Cite this article as: Devi KR, Praneshwari Devi RK, Priya J, Sanaton A, Singh LR, Murray L. A study of congenital anomalies in a tertiary care hospital in North East region, India. Int J Reprod Contracept Obstet Gynecol 2018;7:2899-903. 